University of Nebraska - Lincoln

DigitalCommons@University of Nebraska - Lincoln

USDA National Wildlife Research Center - Staff Publications
U.S. Department of Agriculture: Animal and Plant Health Inspection Service

2011

\title{
Electric shock strips as bird deterrents: does experience count?
}

Thomas W. Seamans

USDA/APHIS/WS National Wildlife Research Center, thomas.w.seamans@aphis.usda.gov

Bradley F. Blackwelll

USDA/APHIS/WS National Widldlife Research Center, bradley.f.blackwell@aphis.usda.gov

Follow this and additional works at: https://digitalcommons.unl.edu/icwdm_usdanwrc

Seamans, Thomas W. and Blackwelll, Bradley F., "Electric shock strips as bird deterrents: does experience count?" (2011). USDA National Wildlife Research Center - Staff Publications. 1364.

https://digitalcommons.unl.edu/icwdm_usdanwrc/1364

This Article is brought to you for free and open access by the U.S. Department of Agriculture: Animal and Plant Health Inspection Service at DigitalCommons@University of Nebraska - Lincoln. It has been accepted for inclusion in USDA National Wildlife Research Center - Staff Publications by an authorized administrator of DigitalCommons@University of Nebraska - Lincoln. 


\title{
Electric shock strips as bird deterrents: does experience count?
}

\author{
Thomas W. Seamans* and Bradley F. Blackwell \\ USDA/APHIS/Wildlife Services/National Wildlife Research Center/Ohio Field Station, 6100 Columbus Avenue, Sandusky, OH \\ 44870, USA
}

(Received 4 April 2011; final version received 24 August 2011)

\begin{abstract}
Understanding how birds detect and react to deterrent methods which are employed to protect structures is important both for the effective control of property damage, and to ensure that human health and safety are not compromised. One such device is a shock strip that causes slight pain to birds when they use a perch. Our aims were to determine: (1) the efficacy of a shock strip to flocks of Brown-headed Cowbirds (Molothrus ater), and Rock Pigeons (Columba livia); (2) the length of time to extinction of effect; (3) whether members of a flock show a behavioural response to treatment; and (4) whether the birds habituate to the treatment. When activated, shock strips were effective in displacing birds from treated areas. Birds had to experience the treatment; there was no discernible indication of flock members reacting to affected birds. When strips were deactivated after an initial period of activation, birds required more than 2 hours to return to treated areas. No habituation was observed. Because birds had to experience the shock, reduced coverage of a structure or use of sham devices to lower costs is considered inadvisable.
\end{abstract}

Keywords: Brown-headed Cowbird; Columbidae; Icterinae; learned behaviour; risk; Rock Pigeon; shock strip

\section{Introduction}

Ironically, the structures and areas designed to enhance the lives of people often provide resources to wildlife species, particularly birds, that are responsible for property damage and threats to human health and safety (Savard et al. 2000). Building architecture provides multiple places for birds to perch or nest, and the subsequent accumulation of guano and nest material can result in a reduction of structural integrity (Feare 1984; Belant 1997). Also, apparently benign locations, such as fences, signs, light fixtures, grass areas, and stormwater ponds, are recognized as attractants to birds that pose hazards to human health and safety at airports (Brough and Bridgman 1980; Blackwell et al. 2008, 2009; Dolbeer et al. 2009). Additionally, bird species, particularly those that are highly adaptable to human-modified environments, can serve as potential sources of zoonoses (Weber 1979; Feare et al. 1999).

Given that birds can both enhance and detract from the quality of life for humans, it is no surprise that solutions to negative bird-human interactions abound. One possible response is the large-scale killing of nuisance bird populations, an approach that is generally undesirable and often impractical (Feare 1984; Dolbeer 1986; Smith et al. 1999; Blackwell et al. 2003). Subsequently, various non-lethal techniques to control bird problems, not all effective, have been evaluated (Bomford and O'Brian 1990; Belant et al. 1998; Blackwell et al. 2002; Avery and Genchi 2004;
Seamans et al. 2007). Inevitably, however, the effectiveness of non-lethal avian deterrents, whether targeting use of structures, food resources, or open areas, requires integration of methods to enable pest management workers to capitalize on aspects of the ecology of the problem species (Dolbeer 1990; Clark 1997).

One aspect of avian behavioural ecology that offers potential for increasing the cost-effectiveness of a deterrent method is communication of risk, by birds that are directly exposed to a stimulus, to naive flock members or even transient individuals. From an individual standpoint (particularly in association with foraging), perception of risk can be innate (Smith 1975; Caldwell and Rubinoff 1983; Schuler and Hesse 1985), learned, or enhanced via learning (Guilford 1990; Clark 1997). Further, in the context of predator-prey relationships, Lima and Dill (1990) contended that animals assess predation risk and make this part of their daily decision-making process. Importantly, risk assessment involves not only direct exposure to the predation event, but the behaviour of conspecifics (Lima 1994; Cresswell et al. 2000). Furthermore, in the context of predation risk, individuals benefiting from other detectors of a potential predation event are likely to be members of the flock or occur in close vicinity to the flock (Lima and Zollner 1996). In addition, perception of risk, again primarily that involving predation, can be enhanced (Curio 1975; Kruuk 1976; Ydenberg and Dill 1986; McLean et al. 1999;

*Corresponding author. Email: thomas.w.seamans@aphis.usda.gov 
Frid and Dill 2002; Griffin 2004). Also, empirical evidence indicates that animals show anti-predator behaviours in response to anthropogenic disturbances (Frid and Dill 2002; Pauli and Buskirk 2002; Blackwell et al. 2009).

Given the ecological basis for animal risk assessment and the applicability of antipredator behaviours toward novel disturbances (e.g. Frid and Dill 2002), the premise that effects of avian deterrent methods might extend beyond individuals directly exposed is reasonable. We questioned, therefore, whether risk associated with a bird deterrent that involves a source of slight pain and is intended to effect displacement of the exposed bird might also cause naive birds within the flock to avoid treated perches. We investigated the reaction of two phylogenetically quite different bird species, both of which are common in humandisturbed landscapes, to a shock-deterrent device. We selected the Brown-headed Cowbird (Molothrus ater) because of its use of edge habitats, particularly those areas modified by humans, and the Rock Pigeon (Columba livia) because it is commonly associated with anthropogenic structures. Our aims were to determine: (1) the efficacy of the technique; (2) the extinction of effect of treatment; (3) whether members of a flock exhibit a behavioural response to the apparent risk posed by treatments, among themselves and to naive flock members; and (4) whether the birds habituate to the shock treatments.

\section{Methods}

\subsection{Bird capture and maintenance}

We captured 150 male Brown-headed Cowbirds in decoy traps in northern Ohio, USA $\left(41^{\circ} 27^{\prime} \mathrm{N}, 82^{\circ} 42^{\prime} \mathrm{W}\right)$ and held them in an enclosed aviary where they were fed a millet-sunflower mix and given water and grit ad libitum. We also collected 90 Rock Pigeons from a private pest control operator (Varmint Guard Environmental Services, Inc., Columbus, Ohio), during August and September 2008 and held them in an outdoor aviary. We fed the Rock Pigeons with a commercial pigeon-feed mixture and provided water ad libitum.

\subsection{Anti-perching experiment}

We used the Bird-shock Flex-Track ${ }^{\mathrm{TM}}$ system (Bird Barrier, Inc., Carson, California, USA) as our antiperching device. We powered the system with a two Dcell battery charger. Each flex-track system was $4.75 \mathrm{~cm}$ wide $\times 0.6 \mathrm{~cm}$ high, with two stainless-steel, braided-mesh tracks attached to an ultraviolet-light stabilized, polyvinylchloride backing that birds must contact to receive a mild electric shock of 0.03 milliamps.

We used two flight cages of $2.4 \mathrm{~m} \times 2.4 \mathrm{~m} \times 1.8$ $\mathrm{m}$, each supplied with two perches that were $107 \mathrm{~cm}$ off the floor and $9.5 \mathrm{~cm}$ wide by $122 \mathrm{~cm}$ long. We fitted two shock strips to each perch so as to completely cover the perch. We randomly selected the treatment cage and used this cage in that format for all experiments. For our experiments with Brownheaded Cowbirds, we provided power to one perch in the treatment cage, whereas the other perch was set up similarly but not supplied with power. For the Rock Pigeon experiments, both perches in the treatment cage were connected to power but only one perch was supplied at any time. In both experiments, perches in the control cage were fitted with shock strips and wiring, but neither perch was connected to power.

We positioned the cages adjacent to each other, but placed a solid barrier between them to prevent visual contact between treatment and control groups. We observed the cages using one American Dynamics Color Camera PrePack 470 TVL High-Resolution with Night Saver video camera (Tyco International, Inc., Princeton, New Jersey, USA) per cage and stored the digital data on a Pelco DX8000 16-channel, 250-gb digital video recorder (Pelco, Clovis, California, USA). Observers at the monitor were screened from the cages by tarpaulins strung between the observation area and the cages.

\subsubsection{Brown-headed Cowbird pre-test}

To determine possible perch preference, we observed birds randomly assigned to treatment and control groups (six groups each for treatment and control; six birds/group; $N=72$ birds) for 1-hour in the respective test cage. Birds assigned to the treatment cage were not exposed to a power-supplied perch during this period. We made spot counts of bird use of all perches after 15, 30 , and 60 minutes post-placement to determine the preferred perch in each cage.

\subsubsection{Brown-headed Cowbird test 1}

In this test, we evaluated the basic efficacy of the system to deter perching. We exposed test groups (six groups each for treatment and control; six naive birds/ group; $N=72$ birds) to treatment and control conditions over $2 \mathrm{~h}$. During this 2-hour period, power was supplied to a randomly selected perch in the treatment cage, based on a finding of no preference during the pre-test phase (see Results). We maintained this perch as the 'powered' perch in each of our tests with the cowbirds. We made spot counts of bird use of perches after $5,10,15,30,60$, and $120 \mathrm{~min}$ post-placement of birds in the cages.

\subsubsection{Brown-headed Cowbird test 2}

Here, we tested the hypothesis that for birds previously exposed to treatment and then exposed for a second 
time to treatment, that there would be an extinction of the effect of treatment within two hours of discontinuing power to the treated perch. Specifically, we were not interested in the effect of period between the initial and next exposure, but whether birds that had experienced treatment on multiple occasions would be successfully deterred from perching. We used birds from the test-1 treatment and control groups (i.e. six groups each for treatment and control; six birds/group; $N=72$ birds) after a period of $0-13$ days between tests. Although we maintained birds relative to their respective assignment to treatment or control groups in test 1 , specific group members were not necessarily the same individuals. After placing birds in each cage, we supplied power to the preselected perch in the treatment cage for 1 hour and made spot counts at 15-minute intervals. At the end of the hour, we turned off the power and observed the flock at 15-minute intervals for up to an additional 75 minutes. We then reviewed the recording to determine when $>50 \%$ of the birds was viewed on the treated perch.

\subsubsection{Brown-headed Cowbird test 3}

In this test we tested the hypothesis that birds which have been previously exposed to treatment indicate this novel threat to birds that are naive to the treatment. We used six groups of naive birds (six birds/group) for treatment and control, respectively. We placed a white ribbon $(2.5 \mathrm{~cm}$ wide by $10 \mathrm{~cm}$ long) on one leg on each of three naive birds, placed them into the treatment cage and supplied power to the shock strip on the preselected perch for 30 minutes. We made spot counts of perch use after 15 and 30 minutes. We then introduced three new birds, each with a black ribbon on one leg, into each cage and made spot counts of perch use after 5, 10, 15, and 30 minutes. We anticipated that removal of power from the treated perch during the time when naive birds were in the cage could bias our results by (1) affording naive individuals immediate perch space on the treated perch, and before any recognition of potential risk-avoidance behaviour from exposed birds; and (2) elimination of possible sensory information associated with electromagnetic fields (Wiltschko and Wiltschko 2005). Thus, we maintained the power to the treated perch after introduction of the three naive birds.

Additionally, we reviewed the video footage and noted the number of times that birds jumped in response to a shock during 1-minute intervals for the first 5 minutes of each half-hour period (i.e. with three birds only, then with six birds in cage). We could not follow individual birds; therefore we report the total number of shocks per interval and ribbon colour. Also, we restrict our comparisons to the second 30-minute period when experienced and naive groups were combined.

\subsubsection{Rock Pigeon test 1}

In this test we again evaluated the basic efficacy of the shock strip and tested the hypothesis that there would be an extinction of the effect of treatment on perch avoidance behaviour within two hours of discontinuing treatment. We used six groups of birds (six birds/ group) for treatment and control, respectively ( $N=72$ birds). We observed each group for 15 minutes, taking spot counts of perch use in the treatment cage at 1minute intervals to determine the preferred (i.e. the perch associated with the highest mean bird use per minute on an absolute scale). During this 15-minute period, there was no power supplied to the perches in the treatment cage. We then supplied power to the preferred perch for 1 hour, turned off the power after the first hour, and continued to observe the cages for an additional two hours. We made spot counts of perch use at 15-minute intervals.

\subsubsection{Rock Pigeon test 2}

As in our test 3 with Brown-headed Cowbirds, we tested the hypothesis that birds previously exposed to treatment would indicate this novel threat to birds that were naive to the treatment. We followed the same procedure in this test as in the cowbird test 3, except for the initial determination of the preferred perch as described in the pigeon test 1 .

\subsubsection{Rock Pigeon test 3}

In this test, we tested the hypothesis that the birds would visually associate the treatment effect with the perch. We marked one randomly selected perch in both the treatment and control cages with yellow (3M Scotch 35 Yellow insulating tape) tape placed perpendicularly to the shock strip at $10-\mathrm{cm}$ intervals, thus creating a contrasting effect. We did not quantify spectral differences between tape and perch. We placed six birds into each cage and determined the preferred perch as described under the pigeon test 1 . We then supplied power to the preferred perch (whether marked or unmarked) in the treatment cage for 30 minutes, and turned off the power thereafter. Next, we entered each cage and switched perches such that the marked perch was placed where the unmarked perch was positioned previously, and the unmarked perch placed where the marked perch had been. We continued observations for an additional 30 minutes, making spot counts of perch use in both cages after 5, 10, 15, and 30 minutes. For this test we used six groups of birds (six birds/group) for treatment and control, respectively ( $N=72$ birds).

\subsubsection{Statistical analysis}

Our response data were not normally distributed, and we were unable to successfully transform them. 
Therefore, we used the Wilcoxon Rank Sum Test to compare bird use (expressed as mean use per observation period) between the two perches in each cage, restricting our comparisons within species and the specific test. We did not compare perch use between treatment and control cages. We evaluated our comparisons at alpha $=0.05$.

\section{Results}

\subsection{Brown-headed Cowbird experiment}

\subsubsection{Pre-test}

Birds in the treated cage showed no preference $(W=0.279 ; P=0.78)$ for either the left $([\bar{x} \pm$ std dev] $3.1 \pm 1.2$ birds/observation $)$ or right $(2.8 \pm 1.1$ birds/observation) perch. In the control cage, we found no significant difference $(W=1.7285 ; P=0.08)$ between bird use of the right ( $3.5 \pm 1.6$ birds/observation) or left ( $2.6 \pm 1.5$ birds/observation) perch.

\subsubsection{Brown-headed Cowbird test 1}

In the treated cage, bird use of the powered perch $(0.8 \pm 1.5$ birds/observation) differed $(W=5.96$; $P=0.00)$ from the control perch $(3.0 \pm 2.2$ birds/ observation). In the control cage, we observed no significant difference $(W=0.63 ; P=0.53)$ between use of the right $(2.0 \pm 1.2 \mathrm{birds} / 5$-min interval $)$ or left $(2.1 \pm 1.2$ birds/5-min interval) perch.

\subsubsection{Brown-headed Cowbird test 2}

After being shocked in test 1 and in this test too, birds preferred $(W=4.06 ; P<0.01)$ the control perch (3.7 \pm 1.5 birds $/ 15$-min interval) over the treated perch $(1.6 \pm 1.7$ birds/15-min interval). After power was turned off, the treated perch was avoided, on average, for $120.5 \mathrm{~min}$ (range $=96-135 \mathrm{~min}$ ) before $\geq$ three birds returned. The control group favoured $(W=2.90 ; \quad P=0.00)$ the right perch $(3.3 \pm 1.1$ birds $/ 15$-min interval) over the left perch $(2.6 \pm 1.0$ birds/15-min interval).

\subsubsection{Brown-headed Cowbird test 3}

During the second 30-min period (i.e. after the naive group was introduced to the cage), the number of shock events received by the experienced group $(0.3 \pm 0.5$ birds shocked $/ \mathrm{min})$ was similar ( $W=0.21 ; P=0.84)$ to those received by the naive group $(0.3 \pm 0.6$ birds shocked $/ \mathrm{min})$. We found no difference $(W=1.19 ; P=0.23)$ in use of the powered perch between groups previously exposed to treatment $(0.0 \pm 0.0$ birds $/ 5$-min interval $)$ and naive groups $(0.0 \pm 0.2$ birds $/ 5$-min interval). In the control cage, birds preferred $(W=3.35 ; P<0.01)$ the left perch $(1.8 \pm 1.0$ birds $)$ over the right perch $(1.2 \pm 1.0$ birds).

\subsection{Rock Pigeon experiment}

\subsubsection{Rock Pigeon test 1}

When power was supplied to the preferred perch, pigeons did not use the perch $(0$ counts on treated perch; $4.7 \pm 2.0$ birds/15-min interval on the control $[W=5.31 ; P=0.00])$. Further, we noted that pigeons preferred the control over treated perch for the 2 hours post-treatment. Although pigeons began returning to the formerly treated perch $(1.1 \pm 1.7$ birds/ 15 -min interval) during the 2 hours of post-treatment, they showed preference $(W=3.28 ; \quad P<0.01)$ for the control perch $(2.4 \pm 2.0$ birds/15-min interval). During the same time in the control cage we observed no significant $(W=0.63 ; P=0.53)$ difference in use of the left $(2.1 \pm 1.2$ birds/15-min interval $)$ or right $(2.0 \pm 1.2 \mathrm{birds} / 15$-min interval $)$ perch.

\subsubsection{Rock Pigeon test 2}

When power was supplied to the preferred perch, we observed no subsequent use of the treated perch during the initial 15-min period. However, after we introduced naive birds into the cage (i.e. for the second 30-min period), we observed that both groups used the treated perch equally ( $W=0.55 ; P=0.58)$, based on the number of shock incidents observed (experienced birds: $2.2 \pm 4.8$ birds/5-min interval; naive birds: $2.1 \pm 3.1$ birds/5-min interval). Also, in examining data for only the previously exposed birds, we found that the number of shock incidents was similar $(W=0.40$; $P=0.69$ ) between the period prior to naive bird introduction $(2.5 \pm 5.0$ birds shocked $/ \mathrm{min}$ interval $)$ and after naive birds were present $(2.2 \pm 4.8$ birds shocked/min interval). Notably, we observed dominant birds, whether experienced or naive, forcing individuals off of the control perch, after which the subdominant bird either flew to the treated perch and was shocked or landed on the floor.

\subsubsection{Rock Pigeon test 3}

Birds did not visually associate the treatment effect with the perch. When we supplied power to the preferred perch, whether the perch was marked (three occasions) or unmarked (three occasions), mean bird use over the observation period of the treated perch ( $n=0$ birds/5-min interval) was less ( $W=6.4$; $P<0.01)$ than that for the control perch $(3.7 \pm 1.5$ birds/5-min interval). When we powered the marked perch (30 min), then removed the power, mean bird use of the marked perch after power was discontinued $(2.0 \pm 1.5$ birds $/ 5$-min interval $)$ did not differ ( $W=0.23 ; P=0.81$ ) from that of the control perch $(2.5 \pm 0.7$ birds $/ 5$-min interval). When we powered the unmarked perch, then removed the power, we found a slight absolute, but not statistically different ( $W=1.87 ; \quad P=0.06)$, use between the marked 
$(1.7 \pm 1.8$ birds/observation period) and unmarked perches $(2.7 \pm 1.8$ birds/observation period $)$. Pigeons in the control cage used marked $(3.0 \pm 1.0 \mathrm{birds} / 5$-min interval) and unmarked $(2.9 \pm 1.0$ birds/5-min interval) perches equally ( $W=0.15 ; P=0.88$ ).

\section{Discussion}

Direct experience of the discomfort provided by the electrical stimulus through the feet of Brown-headed Cowbirds and Rock Pigeons was necessary to keep birds from using perches treated with the shock strips. Specifically, Brown-headed Cowbirds (whether members of the initial treatment group or birds introduced as naive to treatment) exhibited a lack of observational learning (Klopfer 1957; Drickamer and Vessey 1982), as they were not dissuaded from using the treated perch when other birds were shocked in their presence. As happened for Klopfer (1957), this lack of response to the behaviour of experienced flock members may have been due to a cage effect (e.g. the availability of perches) or a lack of time to learn to avoid the perch. Similarly, we found that naive Rock Pigeons were not deterred from using the treated perch by the behaviour of experienced flock members, but issues similar to those observed by Klopfer (1957) might have confounded these results as well. Also, we observed dominance behaviour by the pigeons; this forced subordinate individuals to use the treated perch, an area of higher risk (similar to effects in a "selfish herd", Hamilton 1970).

In addition, there was no discernible evidence that acoustical alarms, whether vocal or non-vocal (Hingee and Magrath 2009), were given when birds were shocked, as birds in both the treated and control cages showed no reaction when a bird experienced the electrical stimulus. However, we cannot eliminate the possibility of an audible or subtle behavioural cue given by a bird being shocked. Still, as most alarm calls or subsequent behaviours were given in the presence of a recognized threat (Lima and Dill 1990; Leavesley and Magrath 2005; Magrath et al. 2007; Fallow and Magrath 2010; Marzluff et al. 2010), we suggest that the birds exposed to treatment did not associate the pain from the shock with a salient cue, such as a predation event (see below). A second possibility, as Lima (1994) found with emberizid sparrows, is that birds likely noticed the behaviour of individuals exposed to treatment, but relied on their own vigilance to detect a threat, rather than responding to the behaviour of the shocked bird (i.e. avoiding false threats). Also, Livingston (1994) conjectured that prey species, such as pigeons, will tend not to display abnormal behaviour resulting from pain or injury, as such behaviour could attract the attention of a predator.

For both species, however, we observed no extinction of treatment effect within two hours posttreatment. We note that $50 \%$ of experienced Brownheaded Cowbirds returned to the treated perch on average by $2.5 \mathrm{~h}$ post-treatment, but Rock Pigeons exhibited a preference for the untreated perch. Although we did not observe dominance-related behaviour in the cowbirds, we do not disregard this possibility. However, the pigeons might associate an area as having an elevated threat, as opposed to a specific object (Lima 1992), such as the treated perch. For example, in the absence of the electrical shock, the pigeons returned to perches previously abandoned (though shifted in position after removal of power), even when perches were differentiated by marking.

With regard to habituation, our experiments were limited in time and therefore it is difficult to determine if birds would habituate to the treatment. However, when a deterrent stimulus is salient in its direct or perceived effect and can be associated with a cue (e.g. secondary chemical repellents; Clark 1997), learning is enhanced and habituation less likely. The probability of habituation is further lessened when the stimulus is unpredictable and alternative resources are available. In the case of birds perching on structures, there are almost always other structures, either man-made or natural, which may serve as alternative perch sites. Additionally, when using shock strips, the birds cannot determine when a shock will occur, but it only occurs on a given perch. The presence of alternative perching areas and consistent discomfort from the shock in our study would, therefore, make habituation unlikely.

Based upon the reactions of the birds in the experiments, as related to the use of shock strips as avian deterrents in structures, deterrence of perching necessitates use of active systems in all accessible parts of the building. Our results suggest that the treatment of "desirable" perch locations will not enhance risk such that less desirable perches are avoided without treatment, nor will the presence of sham anti-perching devices be effective. However, we do not disregard the possibility that a noticeable conditioned stimulus (e.g. a flash of light) associated with the unconditioned stimulus (i.e. the shock) might enhance product efficacy.

\section{Acknowledgements}

We thank R.M. Puzak, Plum Brook Station, for providing access to the study site. M.L. Conger, D.E. Steyer, and L.A. Tyson provided field assistance. T.L. DeVault, J.A. Schmidt, P.M. Schmidt and B.E. Washburn provided editorial comments. Sponsorship and funds for this research were provided by the Federal Aviation Administration (FAA). Mention of companies or commercial products does not imply recommendation or endorsement by the US Department of Agriculture (USDA) over others not mentioned. The USDA neither guarantees nor warrants the standard of any product mentioned. Product names are mentioned solely to report factually on available data and to provide specific information. All of our procedures with birds were approved by the USDA, Animal and Plant Health Inspection Service, Wildlife Services, National Wildlife Research Center (NWRC), Institutional Animal Care and Use Committee prior to the start of our study (QA-1561). Opinions expressed in these studies do not necessarily reflect current FAA policy decisions governing the control of wildlife on or near airports. 


\section{References}

Avery ML, Genchi AC. 2004. Avian perching deterrents on ultrasonic sensors at airport wind-shear alert systems. Wildl Soc Bull. 32:718-725.

Belant JL. 1997. Gulls in urban environments: landscapelevel management to reduce conflict. Landscape Urban Plan. 38:245-258.

Belant JL, Woronecki PP, Dolbeer RA, Seamans TW. 1998. Ineffectiveness of five commercial deterrents for nesting starlings. Wildl Soc Bull. 26:264-268.

Blackwell BF, Bernhardt GE, Dolbeer RA. 2002. Lasers as nonlethal avian repellents. J Wildl Manage. 66:250-258.

Blackwell BF, Huszar E, Linz G, Dolbeer RA. 2003. Lethal control of red-winged blackbirds to manage damage to sunflower: an economic evaluation. J Wildl Manage. 67:818-828.

Blackwell BF, Schafer LM, Helon DA, Linnell MA. 2008. Bird use of stormwater-management ponds: decreasing avian attractants on airports. Landscape Urban Plan. 86:162-170.

Blackwell BF, DeVault TL, Fernández-Juricic E, Dolbeer RA. 2009. Wildlife collisions with aircraft: a missing component of land-use planning on and near airports? Landscape Urban Plan. 93:1-9.

Bomford M, O'Brien PH. 1990. Sonic deterrents in animal damage control: a review of device tests and effectiveness. Wildl Soc Bull. 18:411-422.

Brough TE, Bridgman CJ. 1980. An evaluation of long-grass as a bird deterrent on British airfields. J Appl Ecol. 17: 243-253.

Caldwell GS, Rubinoff RW. 1983. Avoidance of venomous sea snakes by naïve herons and egrets. Auk. 100:195-198.

Clark L. 1997. Physiological, ecological, and evolutionary bases for the avoidance of chemical irritants by birds. Curr Ornithol. 14:2-37.

Cresswell W, Hilton GM, Ruxton RD. 2000. Evidence for a rule governing the avoidance of superfluous escape flights. Proc R Soc Lond B. 267:733-737.

Curio E. 1975. The functional organization of anti-predator behaviour in the pied flycatcher: a study of avian visual perception. Anim Behav. 23:1-115.

Dolbeer RA. 1986. Current status and potential of lethal means of reducing bird damage in agriculture. Int Ornithol Congress. 19:474-483.

Dolbeer RA. 1990. Ornithology and integrated pest management: red-winged blackbirds Agelaius phoeniceus and corn. Ibis. 132:309-322.

Dolbeer RA, Wright SE, Weller J, Begier MJ. 2009. Wildlife strikes to civil aircraft in the United States 1990-2008. Federal Aviation Administration, National Wildlife Strike Database Serial Report Number 15.

Drickamer LC, Vessey SH. 1982. Animal behavior: concepts, processes, and methods. 1st ed. Boston (MA): Willard Grant Press.

Fallow PM, Magrath RD. 2010. Eavesdropping on other species: mutual interspecific understanding of urgency information in avian alarm calls. Anim Behav. 79:411-417.

Feare CJ. 1984. The starling. 1st ed. Oxford: Oxford University Press.

Feare CJ, Sanders MF, Blasco R, Bishop JD. 1999. Canada goose (Branta canadensis) droppings as a potential source of pathogenic bacteria. J R Soc Promo Health. 119:146-155.

Frid A, Dill L. 2002. Human-caused disturbance stimuli as a form of predation risk. Cons Ecol 6:11. Available from: http//www.consecol.org/vol6/iss1/art11

Griffin AS. 2004. Social learning about predators: a review and prospectus. Learn Behav. 32:131-140.
Guilford T. 1990. Insect defenses: adaptive mechanisms and strategies of prey and predators. Albany (NY): State University of New York. Chapter 2, The evolution of aposematism: p. 23-61.

Hamilton WD. 1970. Geometry for the selfish herd. J Theoretical Biol. 31:295-311.

Hingee M, Magrath RD. 2009. Flights of fear: a mechanical wing whistle sounds the alarm in a flocking bird. Proc Royal Soc B. Available from: http://rspb.royalsocietypub lishing.org/content/early/2009/08/28/rspb.2009.1110.full. pdf + html

Klopfer PH. 1957. An experiment with empathic learning in ducks. Am Nat. 91:61-63.

Kruuk H. 1976. The biological function of gulls' attraction towards predators. Anim Behav. 24:146-153.

Leavesley AJ, Magrath RD. 2005. Communicating about danger: urgency alarm calling in a bird. Anim Behav. 70:365-373.

Lima SL. 1992. Strong preferences for apparently dangerous habitats? A consequence of differential escape from predators. Oikos. 64:597-600.

Lima SL. 1994. Collective detection of predatory attack by birds in the absence of alarm signals. J Avian Biol. 25:319-326.

Lima SL, Dill LM. 1990. Behavioral decisions made under the risk of predation: a review and prospectus. Can $\mathbf{J}$ Zool. 68:619-640.

Lima SL, Zollner PA. 1996. Anti-predatory vigilance and the limits to collective detection: visual and spatial separation between foragers. Behav Ecol Sociobiol. 38:355-363.

Livingston A. 1994. Physiological basis for pain perception in animals. J Vet Anaes. 21:73-77.

Magrath RD, Pitcher BJ, Gardner JL. 2007. A mutual understanding? Interspecific responses by birds to each other's aerial alarm call. Behav Ecol. 18:944-951.

Marzluff JM, Walls J, Cornell HN, Withey JC, Craig DP. 2010. Lasting recognition of threatening people by wild American crows. Anim Behav. 79:699-707.

McLean IG, Hölzer C, Studholme BJS. 1999. Teaching predator-recognition to a naïve bird: implications for management. Biol Conserv. 87:123-130.

Pauli JN, Buskirk SW. 2007. Risk-disturbance overrides density dependence in a hunted colonial rodent, the black-tailed prairie dog Cynomys ludovicianus. J Appl Ecol. 44:1219-1230.

Savard JL, Clergeau P, Mennechez G. 2000. Biodiversity concepts and urban ecosystems. Landscape Urban Plan. 48:131-142.

Schuler W, Hesse E. 1985. On the function of warning coloration: a black and yellow pattern inhibits preyattack by naïve domestic chicks. Behav Ecol Sociobiol. $16: 249-255$.

Seamans TW, Barras SC, Bernhardt GE. 2007. Evaluation of two perch deterrents for starlings, blackbirds and pigeons. Int J Pest Manage. 53:45-51.

Smith AE, Craven SR, Curtis PD. 1999. Managing Canada geese in urban environments. Jack Berryman Institution Publication 16, and Cornell University Cooperative Extension, Ithaca, New York.

Smith SM. 1975. Innate recognition of coral snake pattern by a possible avian predator. Science. 187:759-760.

Weber WJ. 1979. Health hazards from pigeons, starlings and English sparrows. 1st ed. Fresno (CA): Thomson Publications.

Wiltschko W, Wiltschko R. 2005. Magnetic orientation and magnetoreception in birds and other animals. J Comp Physiol A. 191:675-693.

Ydenberg RC, Dill LM. 1986. The economics of fleeing from predators. Adv Study Avian Behav. 16:229-249. 